REVIEW ARTICLE

\title{
The amazing world of microorganisms
}

\author{
S.A. Kulasooriya \\ National Institute of Fundamental Studies, Hantane Road, Kandy, Sri Lanka
}

Received: 14/06/2019 ; Accepted: 27/09/2019

\begin{abstract}
Among all living organisms on planet Earth, those that are invisible to the naked eye are the most abundant, most widely distributed and are indispensable for the continuation of life which they themselves originated. This review article has been prepared by going through important historical as well as recent literature on microorganisms with the primary purpose of dissemination of knowledge. It starts with the discovery of microorganisms and takes the reader through the key developments that enabled us to understand the invaluable roles they play in our lives, their possible origin on this planet, their diverse ecosystems and the amazing recent findings of some their existence several kilometers below the Earth's surface. Such subterranean communities appear to possess hitherto little known metabolic systems which are yet to be fully resolved. Moreover, whether these organisms originated in their ultra deep habitats or were transported down from the surface during the early formation of the primitive Earth by processes of subduction is still a matter of speculation. This review article is expected to arouse curiosity to pursue further research studies to unravel more novel information on the diverse activities, ubiquitous distribution and potential utilization of these organisms.
\end{abstract}

Keywords: microbial discovery, microbial origin, ubiquitos distribution, extremophiles, deep subsurface life.

\section{INTRODUCTION}

The discovery of microorganisms by Anton Van Leeuwenhoek (1632 - 1723) brought about a revolution in science. The immediate reaction to this discovery was confusion among taxonomists at that time because all living things had been grouped either as plants or animals. It was not possible to include microorganisms in either group because they not only shared characters common to both but also possessed features unique to them and certain taxonomists called them "Chaos". With the accumulation of knowledge on their morphology, physiology, biochemistry, genetics and molecular biology it became evident that microorganisms are an extremely diverse group of organisms with only one feature in common, their minute size which make them invisible to the unaided eye. The discovery of these organisms led to a new area of science termed Microbiology: the study of microorganisms. Today they are broadly classified into two domains, Prokarya: the prokaryotic (non-nucleated) organisms that include the Archea, Eubacteria, Actinobacteria and Cyanobacteria and Eukarya: the eukaryotic (nucleated) organisms with membrane bound intracelluler organelles, which includes the microscopic algae, fungi and protozoa (Figure 1).

Some of the information in this paper had been published in a much abbreviated version as the Editorial of the Ceylon Journal of Science under the title the fascinating world of microorganisms (Kulasooriya 2018).

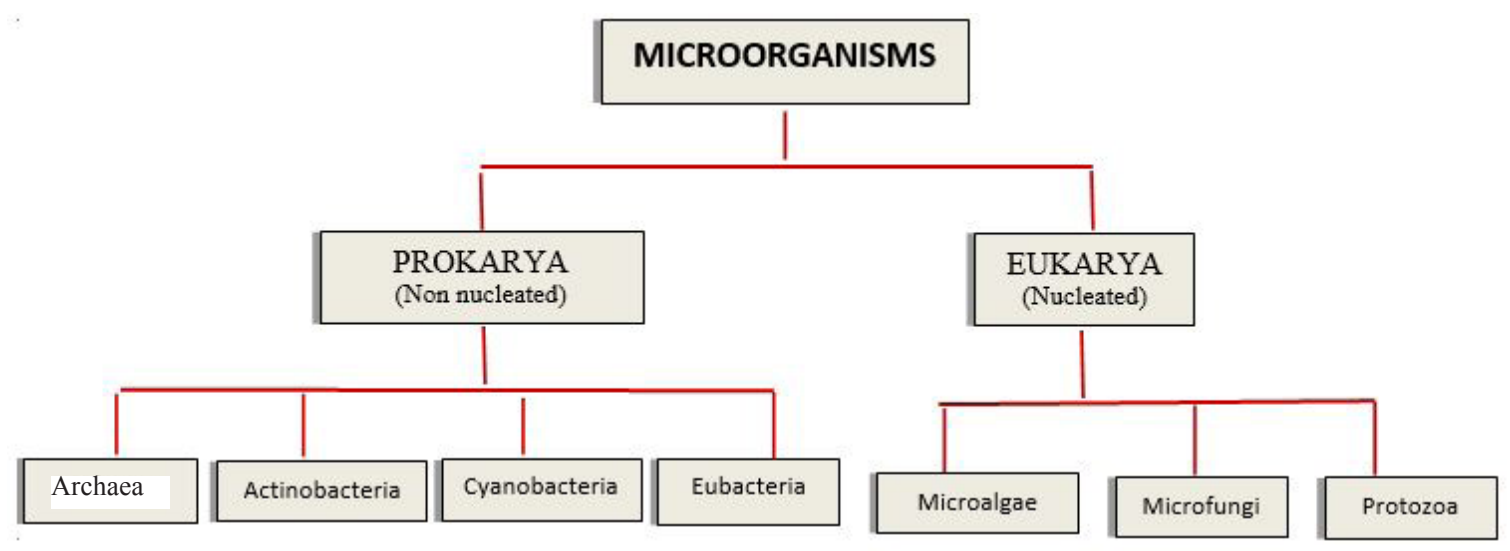

Figure 1: The broad classification of microorganisms. 


\section{HISTORICAL}

Pioneering studies in microbiology were conducted by well known scientists such as Louis Pasteur (1822 - 1895) from France who elucidated technologies of microbial fermentation and pasteurization, formulated the principles of vaccination and provided direct evidence for the 'germ theory of disease'. Together with Ferdinand J. Cohen (1828 - 1898) a German biologist and Robert H. Koch $(1843$ - 1910) a German physician, these three microbiologists are recognized as founders of bacteriology. Using staining techniques, Cohen was the first to carefully observe and group bacteria into three types based on their cell morphology as spherical (Cocci), short rods (Bacilli), threads and spirals (Spirilla) and demonstrated the formation of endospores. Koch identified specific causative agents of tuberculosis, cholera and anthrax, developed innovative techniques of detection and formulated the 'Koch's postulates' that are followed even today as the "gold standards" in medical microbiology. Martinus W. Beijerinck (1851 -1931) was a Dutch microbiologist who is considered as the founder of virology. His results on micro-filtration experiments demonstrated that tobacco mosaic disease is caused by an infectious agent smaller than a bacterium, later named as a virus. Another milestone in medical microbiology was the development of the Gram stain by the Danish microbiologist Hans Christian Gram (1853 - 1935) which enabled the differentiation of bacteria into two major groups based on the their ability to retain or not to retain this special stain after washing with alcohol. It was subsequently found that this characteristic depended upon the complexity of the cell walls of certain bacteria and which bestow upon them the ability to resist certain chemicals applied to destroy them. This simple test is used even today in medical as well as other pathological studies. During these early times when medical scientists continued to unravel that microorganisms were responsible for contagious diseases, many people dreaded these organisms and considered them as germs. This situation became worse when plant and animal pathologists confirmed that several diseases of crops and domesticated animals are also caused by microorganisms and there was a tendency among people at that time to destroy all microorganisms.

These attitudes changed with novel discoveries of the beneficial and vital roles played by microorganisms in the continuation of life on Earth. The initial suggestion of Humphrey Davy (1836) that plants may fix atmospheric nitrogen was demonstrated by Boussinghalt (1838) and Atwater (1885) for symbiotic fixation in legumes and Jodin (1862) for free living microorganisms. Beijerinck (1901) demonstrated aerobic nitrogen fixation by Aerobacter chroococcum and sulfate reduction, a form of anaerobic respiration and Sergei N. Winogradsky (1856-1953) an Ukrainian-Russian microbiologist, soil scientist and ecologist demonstrated anaerobic $\mathrm{N}_{2}$-fixation in Clostridium pasteurianum and also proposed the concept of cycling of nutrients. He also reported that Beggiatoa oxidized hydrogen sulfide $\left(\mathrm{H}_{2} \mathrm{~S}\right)$ as an energy source. His research on nitrifying bacteria reported the first known form of chemoautotrophy and how a lithotroph fixed $\mathrm{CO}_{2}$ to make organic compounds using chemical energy. These discoveries had important implications on the understanding of biogeochemical cycles. Also the improvement and application of biological $\mathrm{N}_{2}$-fixation in crop production gave a special impetus for microorganisms. After centuries of research studies it is now accepted that biological nitrogen fixation is confined to certain prokaryotic microorganisms and their symbiotic associations.

Alexander Fleming (1881 - 1955) British (Scottish) physician, microbiologist and pharmacologist's work discovering lysozyme (Fleming 1922), and demonstrating the first antibiotic penicillin (Fleming 1929) obtained from the fungus Penicillium and the subsequent preparation of a myriad of antibiotics from microorganisms are land mark findings that changed the negative attitudes of society towards microorganisms.

\section{USES OF MICROORGANISMS}

Microorganisms are the primary agents of decomposition of organic matter, an exclusive microbial process that enables the continuation of life on Earth. They may have been used for thousands of years (even prior to their discovery) in the traditional practices of brewing alcoholic drinks and making bakery products. Subsequent to their discovery microorganisms were used to elucidate basic processes of life such as photosynthesis, respiration, metabolism, reproduction and genetics because they can be cultured under controlled conditions to obtain genetically and metabolically uniform populations. In biotechnology and molecular biology including genetic engineering microorganisms are used as tools of genetic exchange. Today some of these organisms are selected, sometimes genetically modified and utilized extensively in the pharmaceutical industries (Russel 2004) and nutraceutical industries (Hugeholtz and Smidt 2002), manufacture of dairy products (Kumar and Chordia 2017), preparation of bio-fertilizers (Kulasooriya et al., 2017), bio-pesticides (Chandler et al., 2011), production of biofuels (Hallenback 2011), eco-friendly agents of sewage treatment (Tahir 2014), cleansing of oil spills (Nature 2010), extraction of valuable metals (Rawlings 2002) and in the development of microbial-fuel cells (Logan et al., 2006).

The modern society therefore looks at microorganisms in a more balanced manner with due recognition to the important roles they play recognizing both positive and negative impacts they have on our lives. According to current thinking nothing more than $1 \%$ of all microorganisms are detrimental to human lives, a significant proportion are beneficial and the vast majority are neutral waiting to be explored and utilized.

\section{ORIGIN AND EVOLUTION}

Let us look at the origins and establishment of life on Earth. The Planet Earth is believed to have cooled down, solidified and formed oceans and terrestrial habitats some 4.8 to 4.5 billion years ago (bya). During the initial billion years chemical or abiotic evolutionary processes in the primordial soup of the oceans are believed to have given 
rise to primitive entities capable of self replication. Various scientists have reported on these processes which have resulted in the formation of amino acids (monomers and proteinoid polymers) that integrated to form aggregates such as protobionts and microspheres with semi-permeable membranes (Hua 2018). Ribose-nucleic acid (RNA) is believed to have been the original hereditary molecule that grew, split and was passed onto the progeny. These gave rise to the earliest life forms on Earth which are believed to be prokaryotic microorganisms. It is most likely that these original prokaryotes were heterotrophic utilizing plenty of organic molecules available in the primordial soup together with those produced by other cells. As these food supplies gradually became limiting some of the cells would have developed strategies to use the readily available solar energy by anaerobic photosynthesis under the anoxic atmosphere prevalent at that time. These archaic processes are still retained by a few pigmented bacterial species like Chlorobium and Rhodospirillum which utilize energy from the sun to reduce $\mathrm{CO}_{2}$ and form organic compounds deriving electrons from substrates such as $\mathrm{H}_{2} \mathrm{~S}$ and $\mathrm{FeS}$ exhibiting non-oxygenic photosynthesis. Olson (2006) has presented possible pathways on the early evolution of photosynthesis primarily based upon fossil evidence during the Archeon Era. According to him the earliest reductant for $\mathrm{CO}_{2}$ fixation (even by primitive cyanobacteria) would have been $\mathrm{H}_{2}$ some 3.8 bya. Proteobacteria and Protocyanobacteria have utilized $\mathrm{Fe}^{2+}$ ions as reductants around 3.0 bya. Evidence of retention of such archaic processes can be observed in certain present day species of cyanobacteria which exhibit light driven $\mathrm{CO}_{2}$ fixation through cyclic photophosphorylation under anaerobic conditions using electron donors such as $\mathrm{H}_{2} \mathrm{~S}$, thiosulfate, or even molecular $\mathrm{H}_{2}$. Cyanobacteria capable of $\mathrm{O}_{2}$ evolving photosynthesis appeared around 2.8 bya, but it took another 5 million years to release this $\mathrm{O}_{2}$ bound to limestone, iron and other minerals to the atmosphere (Olsen 2006). Intense solar rays bombarding the earth converted some of the $\mathrm{O}_{2}$ to $\mathrm{O}_{3}$ which built up a protective $\mathrm{O}_{3}$ layer that enabled the evolution and migration of life forms from the oceans to land.

Towards the beginning of the Proterozoic era the earth began to cool which reduced the hygrometric capacity of air that resulted in continuous torrential rain. These changes of the physical environment led to the proliferation of cyanobacteria in the marine phytoplankton which fixed and stored part of the carbon in the sea. This led to the reduction of $\mathrm{CO}_{2}$ in the atmosphere and released $\mathrm{O}_{2}$ due to oxygenic photosynthesis which would have contributed to the reduction of atmospheric methane through oxidation.

Meanwhile the chloroplasts that are today so common in eukaryotic algae and green plants evolved through processes of endosymbioses between cyanobacteria and heterotrophic eukaryotic ancestors. This endosymbiotic hypothesis originally put forward by Mereschkowsky (1905) was given credence by Martin and Kowallik (1999) by molecular analysis of the higher plant chloroplast genome of Arabidopsis thaliana and comparing it with those of cyanobacteria such as Nostoc punctiforme, Prochlorococcus marinus and Synechocystis sp. PCC 6803 (Martin et al., 2002). The very slow and gradual oxygenation of the atmosphere by the oxygen evolving photosynthesis enabled the development of mechanisms to utilize $\mathrm{O}_{2}$ to secure energy through aerobic respiration. This metabolic process turned out to be far more efficient than the anaerobic processes of fermentation and the aerobes on earth developed at a dramatic pace driving the anaerobes to near extinction. Today aerobes are the predominant living forms among both flora and fauna thriving under an atmosphere containing $21 \%$ of oxygen (Kulasooriya 2011). Tripp et al. (2010) reported on a globally distributed, periodically abundant $\mathrm{N}_{2}$-fixing marine, yet uncultivated, unnamed cyanobacterium designated as UCYN-A. This organism was found to lack the oxygen-producing photosystem-II complex of the photosynthetic apparatus, indicating a novel metabolism. Later UCYN-A was shown to have a symbiotic relationship with a eukaryotic, unicellular prymnesiophyte (Thompson et al., 2012). There are numerous intimate associations among planktonic microorganisms in the deep oceans. For example, Dinophysis acuminata a deep ocean dwelling dinoflagellate engulfs unicellular chlorophytes such as Myrionectra rubra and keep their chloroplasts entrapped to continue photosynthesis and provide it nutrition for months (Dorell and Howe 2012). Such intercellular interactions in the oligotrophic deep oceans may be reflecting similar relationships that may have resulted in the evolution of chloroplasts in the primitive Earth in which cyanobacteria and other prokaryotes were predominant. Found among the ocean phytoplankton is a little known cyanobacterium Prochlorococcus marinus, the tiniest photosynthetic organism and the most populous autotroph in the oceans. These populations represent a unique case among the present day microorganisms. Their vast populations in the oligotrophic deep oceans make a significant contribution to primary production and $\mathrm{C}$-sequestration that ameliorates global warming especially in view of the fact that over $70 \%$ of the Earth's surface is covered by the oceans. Another remarkable finding is the close association Prochlorococcus cells are having with numerous viruses that facilitate rapid lateral gene transfers among them. Such transfers endow upon them an intrinsic ability to display an array of physiological differences regulated by the genetic diversity of their constituent cells. This diversity provides an extraordinary stability to this homogenous, but heterogenomic population which internally adjusts itself to the rapidly changing environmental conditions (Johnson et al. 2006).

\section{GLOBAL DISTRIBUTION}

Microorganisms are ubiquitous in their global distribution (Figure 2). They occupy a broad range of habitats across all latitudes and longitudes and are widespread in freshwater, marine and terrestrial ecosystems. They are the most populous living plankton organisms in the vast oceans that cover over $70 \%$ of the Earth's surface. Frequently they are the pioneer invaders of exposed terrestrial habitats such as bare rocks, recently piled up soil or bare land after natural disasters. They are also common inhabitants of polluted water bodies, drains, garbage and industrial dumps which are generally inhospitable to most other organisms. The 


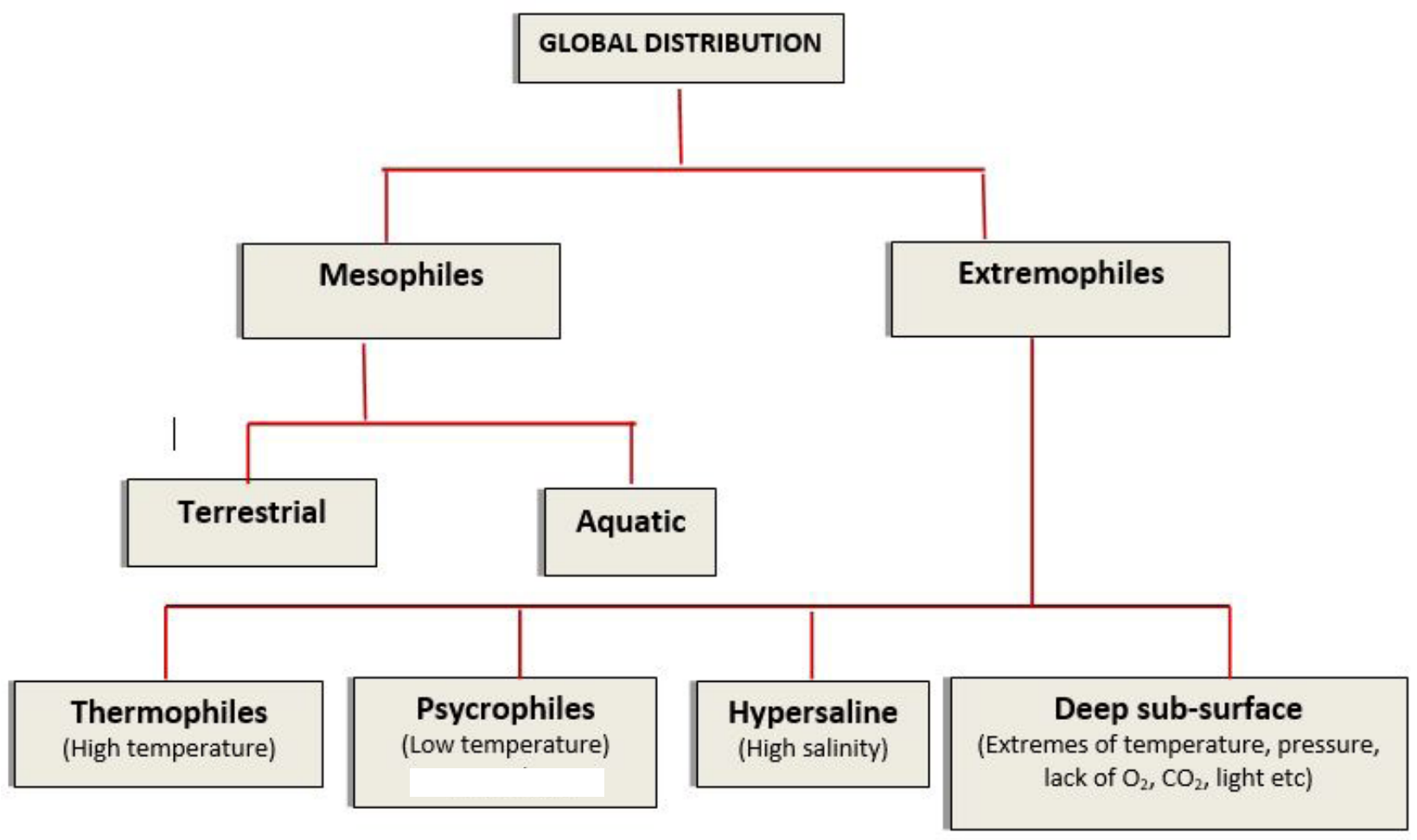

Figure 2: Major distributional groups of microorganisms.

versatile abilities of these organisms and the intimate relationships including endosymbiosis they exhibit with all other forms of life are perhaps reflections of their pioneering ancestry in which they were the only organisms living in the primitive Earth. The widespread symbiotic relationships between prokaryotic microorganisms and all other living organisms on Earth had given rise to novel theories of Symbiogenic Evolution (Carrapico 2012). This concept suggests that besides the theories of Darwinism and Neo-Darwinism, symbiotic relationships had played a decisive role in the evolution of eukaryotic organisms like higher plants and animals including man.

Besides mutation, genetic recombination and natural selection, evolution would have involved symbiotic associations between organisms to form consortia of new structural dimensions. Thus most eukaryotic organisms are really consortia of organisms functioning in harmony towards common goals of development and adaptation. It had been reported that the body of a human carries microorganisms, the population of which outnumber the total number of cells in its tissues. Some of these internal associations are vital for the normal functioning of our systems (Llyod-Price et al., 2016 and Davis 2018). Soil microorganisms seldom associate individually with higher plants but more as consortia of microorganisms (Seneviratne and Kulasooriya 2013) and this feature had been adapted to develop novel biofilm-biofertilizers (Seneviratne et al., 2011).

\section{EXTREMOPHILES}

These are organisms found in extreme habitats such as hot springs, hypersaline localities, freezing environments and arid deserts. For example, Geogemma barossii a prokaryotic member of the Archaea, is able to reproduce at $121^{\circ} \mathrm{C}$ and lives associated with extremely hot hydrothermal vents in the ocean floor. Halophilic microorganisms occupying hypersaline habitats both above and below ground ecosystems present a myriad of intriguing physiological and biochemical systems, some of which are not yet fully understood (Javor 1989 and Ali et al., 2016). Common hypersaline inhabitants are bacterial genera such as Pseudomonas, Flavobacterium, Chromobacterium, Halobacterium, Clostridium, Sporohalobacterium, Holomonas and a novel species Halobaculum gomorrense (Archaea). An obligate halophylic fungus belonging to the Genus Aspergillus had been recorded from the Dead Sea (Nazareth et al., 2012) and another eukaryotic fungus Hortaea werneckii had also been isolated. Among the photosynthetic organisms Aphanotheca halophytica (cyanobacterium), Chlamydomonas nivalis and Dunaliella salina (green algae) and a red, thermophilic Cyanidium caldarium had been recorded. Besides these, an entirely new biosphere of microorganisms had been recorded associated with rock salts buried deep within salt depositions that have taken place during the late Permian and early Triassic periods some 240 to 280 million years ago. Fendrihan et al., (2006) have written a comprehensive review article on the viable haloarchaea in rock salts, citing most of the published literature up to that time. According to available evidence extensive salt sediments had developed in large basins due to evaporation under the warm and arid belt around the equator in the Pangaean supercontinent. The Pangaea started to break up some 100 million years ago and continents began to separate from one another together with folding of new mountain ranges such as the Alps and the Capathians. These movements driven by plate 


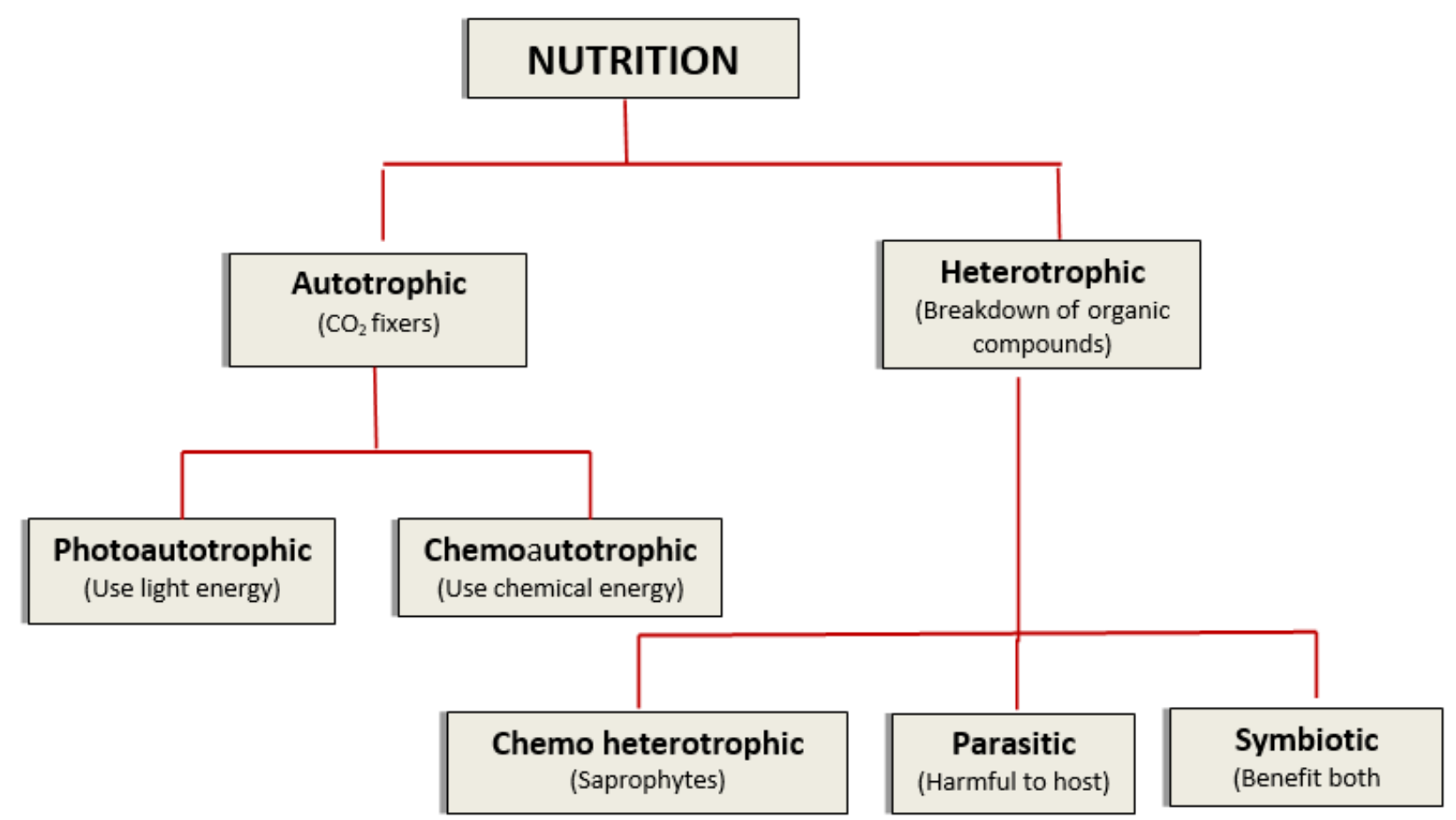

Figure 3: Nutritional diversity among microorganisms.

tectonics gave rise to huge subterranean salt deposits in Siberia, Northern and Central Europe, South-Eastern Europe and the mid Continental basin in North America. The examination and analysis of rock salt samples mined from these deeply buried salt mines have revealed a whole lot of novel microorganisms.

Research studies on such extremophiles are conducted to understand the enzymes and/or metabolic systems that operate within these cells as they could possess special features useful for practical applications.

\section{THE DEEP SUBTERRANEAN MICROORGANISMS}

A remarkable finding is the discovery of a vast array of hitherto unknown microorganisms underneath the surface of the Earth. One of the most fascinating discoveries of recent times is the finding of vast assemblages of diverse microorganisms beneath the sea bed of the Earth's oceans including the glacial regions of the Arctic and the Antarctic. Jonathan Watts (2018) a science journalist, had written on the reports of 1200 scientists from 52 countries in disciplines ranging from geology, microbiology, chemistry and physics on the conclusion of a 10-year study, the findings of which were presented before the American Geophysical Union's annual meeting in December 2018. Some of these reports are providing photographic evidence of a eukaryotic nematode found 1.4 kilometers below the surface of the ocean floor living among a biofilm of microorganisms. This nematode tentatively identified as a species belonging to the Genus Poikilolaimus had been observed from samples of a bore hole dug into the Kopanag Gold Mine in South Africa. A more elaborate report entitled Life in Deep Earth had also appeared in Science Daily of December 10,2018 . What had been unraveled by these studies on this deep biosphere is truly amazing. The vast majority of this biosphere constitutes of prokaryotic microorganisms belonging to the archaea and bacteria. Collating information gathered by the Deep Carbon Observatory from bore holes drilled down to $2.5 \mathrm{Km}$ depths and analyzing samples obtained from continental mines and bore holes $5 \mathrm{Km}$ deep, scientists have been able to make models and predict the possible dimensions of this enormous sub-surface biosphere of the Earth. It is now hypothesized that nearly $90 \%$ of the Earth's carbon is in the sub-surface interior and all the carbon in the vegetations that we encounter above ground is minimal. It is approximately estimated that the mass of below ground carbon is in the range of 15 to 23 billion metric tons, which is 245 to 385 times greater than the carbon mass of all humans (reported by science writer Jennifer Frazer in the Scientific American of January, 23, 2019). Although these astonishing findings have been reported mostly during the last decade, the possibility of the existence of such organisms had been predicted in 1920 by Edson S. Bastin, a Geologist of the University of Chicago. On the observations that water from deep oil wells contained hydrogen sulphide and bicarbonate, he suggested that there could be anaerobic bacteria using such substrates existing deep underneath. Together with Frank E. Greer a microbiologist colleague from the same university, they reported on the successful culturing of $\mathrm{SO}_{4}$ reducing bacteria in 1926 isolated from ground water samples from oil deposits hundreds of meters below the surface. From 1940s to 50s Claude E. Zobelle and colleagues investigated microbial processes far below the ocean bed, but interest in sub-surface microbiology then diminished. During the 1960s and 70s most microbiologists believed that microbes found in such deep water samples are surface contaminants. However, research findings reported during the past five years are revealing an entirely new biosphere of billions of microbes whose genetic diversity appears to be equal to those found above ground (Gabbatiss 2018). This is also one of the reports included in the 10 year study of the Deep 
Carbon Observatory group of scientists.

The confirmation of the finding of this enormous subterranean biosphere of microorganisms had opened up a new microbial world for future scientific research. How did these microbes get there? Were they part of the primitive surface life forms of early evolution under the archaic anaerobic Earth transported down by subduction or did they evolve by themselves in their subsurface novel environment? Both these processes are likely to have happened.

Balkwill and Boone (1977) have cultured, identified, preserved and catalogued 9000 strains of microorganisms from subsurface environments and only 100 of them are fungi. Inagaki et al., (2015) provided remarkable evidence for the existence of microbial communities in $40^{\circ}$ to $60^{\circ} \mathrm{C}$ sediments associated with lignite coal beds at 1.5 to 2.5 $\mathrm{km}$ below the sea floor in the Pacific Ocean off Japan. The population densities of these communities ranged from less than 10 to $10^{4}$ cells per $\mathrm{cm}^{3}$ far less than those of the surface communities. Highest population densities were observed in the lignite layers and these communities differed markedly from the shallow subsurface layers, but resembled organotrophic communities in forest soils. They suggested that terrigenous sediments retain indigenous community members tens of millions of years after their burial in the sea bed. This is truly amazing. Applying biomarkers, analyzing isotopic compositions of methane and $\mathrm{CO}_{2}$, cultivation data and gas compositions, microbial methanogenesis had been suggested as their major form of metabolism. Existence of such deep subsurface microbial communities associated with coal shales have been confirmed by Trembarth-Reichert et al., (2017). With all this overwhelming recent evidence there is no doubt that there is a huge microbial world underneath the surface of the Earth perhaps extending down to about $5 \mathrm{~km}$.

In either case it is intriguing and perhaps still not completely resolved how they conduct their cell metabolic activities and continue to live and reproduce in these ultra deep ecosystems. Basic questions on how they survive the extremes of pressure and temperature in these habitats and their sources of energy in the absence of any replenishment of organic carbon from the surface are yet to be answered.

There had been a few reports on the metabolism of these organisms grouped together as Subsurface, Lithoautotrophic Microbial Ecosystems (SLiMES). It is postulated that like in many anaerobic ecosystems, SLiMES could be dependent upon syntrophic intercellular hydrogen transfer. $\mathrm{H}_{2}$ driven processes are nothing new among microorganisms and there are many reports of such processes supporting the survival of surface dwelling anaerobic species. What is yet to be fully demonstrated is proof of the persistence of long term, hydrogen-driven communities independent of the products of photosynthesis. A body of evidence is building up on the existence of SLiME like communities wholly dependent upon $\mathrm{H}_{2}$ metabolism and this has implications not only for deep subsurface life on Earth, but also for the possible existence of such life in other worlds (Nealson et al., 2005). In a more recent report it has been demonstrated that SLiMES under oligotrophic conditions are typically supported by $\mathrm{H}_{2}$ Methanogens and sulfate reducers (Lau et al., 2016). According to these authors the anaerobic energy transfer processes of these organisms are the key players in the microbial communities of the fluid filled deep fractures of the Willwaterstand Basin of South Africa.

Irrespective of the metabolic processes adopted by these subsurface organisms, it has been generally observed that their metabolic activities are very low and growth and cell division rates are unbelievably slow. Duda et al., (2012) reported on a community of ultramicrobacteria of less than $0.1 \mu^{3}$ containing 0.58 to $3.2 \mathrm{Mb}$ genomes. They appear as starved, tiny and dwarfed microbes with much lower metabolic rates with average frequency of cell divisions being as low as once in a century or less! They can be considered as surviving in suspended animation or virtual hibernation on geologic time scales, but remains viable at minimal metabolic cost.

\section{CONCLUSION}

It is evident from the foregoing that the Microbial World today presents an array of different microscopic organisms with a very wide range of diversity in all aspects of their lives. It is a reflection of their archaic ancestry commencing from the very beginning of life on Earth. It should also be realized that they present an invaluable germplasm which originated around 3.8 billion years ago that had undergone evolution and natural selection in harmony with all the changes undergone by the Earth. It is necessary to understand that there is plenty more to discover in this fascinating microbial world and it is our foremost responsibility to protect this natural storehouse of diverse genes and conserve them for future exploration and utilization. The novelty of this review article is the revelation of the existence of the diverse and enormous subterranean biosphere that exists several kilometers below the Earth's surface. More and more information of these vast ecosystems are gathering as evident from the recent literature. This appears to be an area open for novel integrated studies among Geochemists, Microbiologists, Biochemists and deep sub-surface Ecologists all over the world.

\section{REFERENCES}

Ali, I., Prasongsuk, S., Akbar, A., Aslam, M., Lotrakul, P., Punnapayak, H., \& Rakshit, S. K. (2016). Hypersaline habitats and halophilic microorganisms. Maejo International Journal of Science and Technology, 10(3), 330-345.

Atwater, W.O. (1885) On the acquisition of atmospheric nitrogen by plants. American Chemical Journal, 6: 365 -388 .

Balkwill, D.L. and Boone, D.R. (1977) Identity and Diversity of Microorgansms cultured from Subsurface Environments. In: The Microbiology of the Terrestrial Deep Subsurface. (eds) Penny S. Amy and Dana L. Haldeman, CRC Lewis Publ., Boca Raton, New York: 105-118.

Beijerinck, M.W. (1901) Uber oligonitrophile Mikroben. Centr. Bakteriol. Parasitenk. Abt. II, 7: 561-565.

Boussingalt, J. (1838) Reserches chemiques sur la 
vegetation enterprises dans le but d'examiner si les plantes prennet de l'azote de l'atmosphere. Annals Chimica and Physica, 67: 1-54.

Carrapico, F. (2015) Beyond neo-Darwinism. Building a Symbiogenic Theory of Evolution. Kairos Revista de Filosophia and Ciencia 12: 47-53.

Chandler, D., Bailey, A. S., Tatchell, G. M., Davidson, G., Greaves, J and Grant, W. P. (2011).

The development, regulation and use of biopesticides for integrated pest management, Philosophical Transactions, Royal Society London B, Biological Sciences 366(1573): 1987-1998.

Davis, N. (2018) The Human Microbiome: Why our own microbes could be key to our health, The Guardian, Monday 26.

Davy, H (1836) Elements of agricultural chemistry, $5^{\text {th }}$ Edition, Lonodon Longmans: 378p.

Dorrel, R. G. and Howe, C. J. (2012) What makes a chloroplast? Reconstructing the establishment of photosynthetic endosymbiosis. Journal of Cell Science 125(8): 1865-1875. doi : 10.1242/jcs.102285.

Duda, V.L., Suzina, N.E., Polivtseva, V.N. and Boronin, A.M. (2012) Ultramicrobacteria. Mikrobiologiya, 81(4): 415 - 427.

Fendrihan, S., Andrea, L., Manon, P., Claudia, G., Gerhard, W., Fedrich, G. and Helga, Stan-Lotter. (2006) Extremely halophilic archaea and the issue of long microbial survival. Rev. Environ. Sci. Biotechnol. Aug 5(2-3): 201-218. doi: 10.1007/is11157.006.0007.y .

Fleming, A. (1922) On a remarkable bacteriolytic element found in tissues and secretions. Proceedings of the Royal Society of London. Series B, Containing Papers of a Biological Character 93(653), 306-317.

Fleming, A. (1929) On the antibacterial action of cultures of a penicillium with special reference to their use in the isolation of B.influenzae. Bristish journal of experimental pathology, 10: 226-236.

Gabbatiss, J. (2018) Massive deep life study reveals tons of microbes living far beneath the Earth's surface. The Independent, December 11:14 - 22.

Gram, H.C. (1884). "Über die isolierte Färbung der Schizomyceten in Schnitt- und Trockenpräparaten". Fortschritte der Medizin (in German) 2: 185-189. with An English translation is in Brock, T.D. (1999). Milestones in Microbiology 1546-1940 (2 ed.). ASM Press. pp. 215-218.

Hallenbeck, P.C. (2011) (ed) Microbiological Technologies in Advanced Biofuels Production, ISBN 978-1-46141207-6 e-ISBN 978-1-4614-1208-3 DOI 10.1007/9781-4614-1208-3 Springer New York, Dordrecht, Heidelberg, London.

Hua Zhu (2018) On the Origin of Life: A Possible Way from Fox's Microspheres into Primitive Life, Symbiosis, Opinion Article, SOJ Biochemistry, Open Access Article, November 2018, DOI:10.15226/23764589/4/1/00130: 5pp.

Hugenholtz, J. and Smid, E. \J. (2002) Nutraceutical production with food-grade microorganisms, Current Opinion in Biotechnology 13(5): 497-507.

Inagaki, F. et al (45 co-authors) (2015) Exploring deep microbial life in coal bearing sediment down to $2.5 \mathrm{~km}$ below the ocean floor. Science 349(6246): 420-424.

Javor, B. (1989) Hypersaline Environments, Microbiology and Biogeochemistry, Springer-Verlag, Berlin.

Jodin, C.R. (1862) Du réle physiologique de l'azote faisant suite 5 un précédant travail présenté a l'Acadérnie dans la séance du 28 avril 1862. Acad. sci. Du réle physiologique Paris 55: 612-615.

Johnson, I. Zackary, Zinser, Erik R., Coe, Allison, McNulty, Nathan P. E., Woodward, Malcolm S. and Chisholm, Sally M. (2006). Niche partitioning among Prochlorococcus ecotypes along ocean-scale environmental gradients. Science 311(5768): 17371740.

Kulasooriya, S.A. (2011) Cyanobacteria: Pioneers of Planet Earth. Ceylon Journal of Science, (Bio. Sci.) 40(2): 7188.

Kulasooriya, S.A., Seneviratne, G. and Ekanayake, E. M. H. G. S. (2017), Soil microbial biodiversity and its utilization in Agriculture in Sri Lanka, Chapter 09, In: J. K. Patra etal (eds) Microbial Biotechnology, Springer Nature, Singapore Pte Ltd: 204-223. doi. org/10.1007/978-981-10-6847-8_9.

Kulasooriya, S.A. (2018), The fascinating world of microorganisms. Editorial, Ceylon Journal of Science 47(1): $1-2$.

Kumar, A. and Nikita, C. (2017) Role of microbes in Dairy Industry, Nutritional Food Science International, Mini review 3(3) - DOI: 10.19080/NFSIJ.2017.03.555612

Lau, M., et al (22 co-authors) (2016) An oligotrophic deep-subsurface community dependent on syntrophy is dominated by sulfur-driven autotrophic denitrifiers. Proceedings of the National Academy of Sciences, 113(49):122-144.

Lloyd-Price, J., Abu-Ali, G and Huttenhower, C. (2016) The healthy human microbiome, Genome Medicine, 8: 51-75. Doi: 10.1186/s13073-016-0307-y.

Logan, B.E., Hamerlers, B., Rosendal, R., Der, J.U., Keller, R. G., Freguia, S., Aelterman, P. and Rabaey, K (2006) Microbial Fuel Cells: Methodology and Technology, American Chemical Society 40 (17): 51-81.

Martin, W. and Kowallik, K.V. (1999). Annonated English translation of Mereschkowskiees 1905 paper. European Journal of Phycology. 34 (3): 287-295.

Martin, W., Rujan, T., Richly, E., Hamen, A., Cornelsen, S., Lin, T., Leister, D., Stoebe, B., Hasegawa, M. and Penny, D. (2002). Evolutionary analysis of Arabidopsis, cyanobacteria and chloroplast genomes reveals plastid phylogeny and thousands of cyanobacterial genes in the nucleus. Proceedings of the National Academy of Science, USA 99: 12246-12251.

Mereschkowsky, C. (1905). Uber Natur und Ursprung der Chromatophoren im Pflanzenreiche. Biologie Centrabl. 25: 593-604.

Nature Reviews (2010) Oil Spills: microorganisms to the rescue, Editorial, Nature Reviews Microbiology, 01, July, 2010, 8: 462

Nazareth, S., Gonsalves, V. and Nayak, S. (2012) A first record of an obligate halophilic Aspergillus from the Dead Sea. Indian Journal of Microbiology 52: 22- 27.

Nealson, K.H., Fumio, I. and Ken, T. (2005) Hydrogendriven subsurface lithoautotrophic microbial 
ecosystems (SLiMES): do they exist and why should we care? TRENDS in Microbiology, 13(9): 405-410.

Olson, J.M. ( 2006). Photosynthesis in the Archean Era. Photosynthesis Research, 88: 109-17.

Rawlings, D.E. (2002) Heavy metal mining using Microbes, Annual Rview of Microbiology, 56: 65-91, doi: 10.1146/annurev.micro.56.012302.161052

Russel, A.D. (2004) Additional applications of microorganisms in the pharmaceutical Sciences, Chapter 25, In Pharmaceutical Microbiology (eds) Stephen P. Denver and Norman A. Hodges, 7th Edition, Wiley online, Blackwell Science Publishers: pgs 441457, https://doi.org/10.1002/9780470988329.ch25.

Seneviratne, G., Jayasekera, A.P.D.A.. De Silva, M.S.D.L. and Abeysekera, U.P. (2011) Developed microbial biofilms can restore deteriorated conventional agricultural soils. Soil Biology Biochemistry, 43: 1059 $-1062$.

Seneviratne, G. and Kulasooriya, S.A. (2013), Reinstating soil microbial diversity inagroecosystems: the need of the hour for sustainability and health. Agricultural Ecosystem and Environment. 164: 181-182.

Tahir, F. (2014) Microbiology of Sewage and Sewage Treatment. Environmental Microbiology, MCB 503.

Thompson, A.W., Foster, R.A., Krupke, A., Carter, B.J., Musat, N., Vaulot, D., Kuypers M.M.M. and Zehr, J.P. (2012). Unicellular cyanobacterium symbiotic with a single celled eukaryotic alga. Science 337: 1546-1550. DOI: http://dx.doi.org/10.1126/science.1222700110.

Trembath-Reichert, E., Yuki M., Akira I., Tatshuhiko, H., Katherine, S.D., Fumio, I. and Victoria, J.O. (2017) Proceedings of the National Academy of Sciences, Doi 201707525.

Tripp, J.H., Bench, S.R., Turk, K.A., Foster, R.A., Desany, B.A., Niazi, F., Affourtit, J.P. and Zehr, J.P. (2010). Metabolic streamlining in an open-ocean nitrogen fixing cyanobacterium. Nature 464: 90-94. DOI: http:// dx.doi.org/10.1038/nature08786112. 